\title{
Effect of reservoir pressure and total organic content on adsorbed gas production in shale reservoirs: a numerical modelling study
}

\author{
Moataz Mansi ${ }^{1}$ [D $\cdot$ Mohamed Almobarak ${ }^{1} \cdot$ Christopher Lagat $^{1} \cdot$ Quan Xie $^{1}$
}

Received: 7 July 2021 / Accepted: 28 December 2021 / Published online: 10 January 2022

(c) The Author(s) 2022

\begin{abstract}
Adsorbed gas plays a key role in organic-rich shale gas production due to its potential to contribute up to $60 \%$ of the total gas production. The amount of gas potentially adsorbed on organic-rich shale is controlled by thermal maturity, total organic content (TOC), and reservoir pressure. Whilst those factors have been extensively studied in literature, the factors governing desorption behaviour have not been elucidated, presenting a substantial impediment in managing and predicting the performance of shale gas reservoirs. Therefore, in this paper, a simulation study was carried out to examine the effect of reservoir depth and TOC on the contribution of adsorbed gas to shale gas production. The multi-porosity and multi-permeability model, hydraulic fractures, and local grid refinements were incorporated in the numerical modelling to simulate gas storage and transient behaviour within matrix and fracture regions. The model was then calibrated using core data analysis from literature for Barnett shales. Sensitivity analysis was performed on a range of reservoir depth and TOC to quantify and investigate the contribution of adsorbed gas to total gas production. The simulation results show the contribution of adsorbed gas to shale gas production decreases with increasing reservoir depth regardless of TOC. In contrast, the contribution increases with increasing TOC. However, the impact of TOC on the contribution of adsorbed gas production becomes minor with increasing reservoir depth (pressure). Moreover, the results suggest that adsorbed gas may contribute up to $26 \%$ of the total gas production in shallow (below 4,000 feet) shale plays. These study findings highlight the importance of Langmuir isothermal behaviour in shallow shale plays and enhance understanding of desorption behaviour in shale reservoirs; they offer significant contributions to reaching the target of net-zero $\mathrm{CO}_{2}$ emissions for energy transitions by exhibiting insights in the application of enhanced shale gas recovery and $\mathrm{CO}_{2}$ sequestration - in particular, the simulation results suggest that $\mathrm{CO}_{2}$ injection into shallow shale reservoirs rich in TOC, would give a much better performance to unlock the adsorbed gas and sequestrate $\mathrm{CO}_{2}$ compared to deep shales.
\end{abstract}

Keywords Adsorbed gas $\cdot$ Barnett shale $\cdot$ Langmuir isotherm

\section{Introduction}

Shale gas resources have been identified as an important component in current clean geo-energy, which plays an important role in the energy transition to net-zero target of carbon dioxide emission. Therefore, in recent years, there has been increasing interest in the commercial development

Responsible Editor: Santanu Banerjee

Moataz Mansi

moataz.mansi@postgrad.curtin.edu.au

1 Discipline of Petroleum Engineering, WA School of Mines: Minerals, Energy and Chemical Engineering, Curtin University, Perth, Western Australia, Australia of shale gas resources worldwide; in 2018, shale gas accounted nearly $65 \%$ of The United States (U.S.) total gas production (IEA 2019), and 21\% in China (Dai, Qin et al. 2019). This significant breakthrough in the exploitation of shale gas resources has extended to other countries such as Canada and Australia. However, shale gas reservoirs have presented new challenges due to their ultra-low permeability and recovery factors (Bybee 2009). Consequently, it is essential to enhance the matrix permeability to achieve economical production from shale reservoirs.

The advanced technologies of horizontal drilling and multi-stage hydraulic fracturing techniques create and establish the conductivity between fractures and matrix with induced fractures network. These technologies enable the oil and gas industry to achieve the shale gas reservoirs' 
potential with commercial production. Similar to coalbed methane, shale gas reservoirs hold a tremendous amount of gas on the surface of organic minerals which can be referred to as the adsorbed gas (Kang et al. 2010). The adsorbed gas has been a key parameter in shale gas reservoirs evaluation and development and may count up to $60 \%$ of the total gas in place (Wu et al. 2014). Unlocking adsorbed methane on organic-rich shale surface has attracted great attention in industry due to its potential to produce considerable amounts of gas.

The adsorption and desorption phenomenon has been investigated in a large, growing body of literature. Although several studies have widely focused on adsorption behaviour (Ji, Zhang et al. 2012, Gasparik et al. 2013, Hardy 2019), desorption behaviour has not been completely elucidated, presenting a substantial impediment in the efficient management and performance predictions of shale gas reservoirs. Of the few studies identifying factors governing desorption in shale gas production, some have focused only on the impact of hydraulic fracture parameters on both free and adsorbed gas (Freeman, Moridis et al. 2013, Pan and Connell 2015). Researchers have investigated the influencing reservoir parameters on shale production (Bumb and McKee 1988, Mengal and Wattenbarger 2011) - however, the multi-porosity and diffusion models have not been considered in their studies. Further investigations considering the aforementioned models (Zhang, Du et al. 2009, Wasaki and Akkutlu 2015a, b) have neglected the effect of total organic content (TOC) and the impact of reservoir pressure.

Currently, research regarding the parameters governing the contribution of adsorbed gas to shale production is lacking. Whilst several sensitivities studies have been carried out in the literature to evaluate the desorption behaviour, however, to the best of our knowledge, no single study exists which has considered the multi-permeability and diffusion models to investigate the impact of reservoir depth on the production of adsorbed gas considering TOC. Therefore, there is a pressing need to combine all these models to examine the impact of reservoir depth (i.e. pressure) coupled with TOC on adsorbed gas production performance in shale gas reservoirs.

In this work, we employ multi-porosity and multi-permeability model incorporating with Langmuir isotherms and instant sorption option to quantify the contribution of adsorbed gas to total gas production. In particular, this research seeks to investigate the factors influencing adsorbed gas production in shale reservoirs. The sensitivity analysis aims to provide a greater understating of transient and desorption behaviour with respect to reservoir depth and TOC. The results of this paper could provide important insights into the selection of optimal depth to inject $\mathrm{CO}_{2}$ in shale reservoirs which can potentially enhance both $\mathrm{CH}_{4}$ recovery and $\mathrm{CO}_{2}$ sequestration.
This study has been divided into five parts: the first part includes this introductory section. The second consists of a brief overview focusing on the key theory of shale gas reservoirs production and modelling. Thirdly, the methodology used for this study including model development and calibration will be covered. The fourth section presents the simulation results and discussion. Finally, the conclusion gives a summary of the findings and implications.

\section{Theory}

\section{Shale gas production}

Shale gas mainly exists in three different forms: (a) free gas in the fractures with various length scale and in the interconnected micro-pores of the organic content (Godec, Koperna et al. 2014); (b) adsorbed gas on the organic surfaces; and (c) dissolved gas in the reservoir fluids (Kang et al. 2010). The primary production profile of a single shale well dramatically declines after a few years of high initial production rate. As the reservoir pressure declines, adsorbed gas begins to be desorbed from the organic matter surface contributing to the total production with a considerable amount account up to $60 \%$ of the total gas in Wu et al. 2014). This stage of production extends and contributes significantly to the cumulative production.

Figure 1 shows the gas primary production profile for the base case from our simulation results. Therefore, the contribution of adsorbed gas in production has been considered as a pintail of shale reservoir long-term production (Bumb and McKee 1988). However, challenges arise when quantifying and predicting the recoverable adsorbed gas due to complex transport of desorbed gas within organic and matrix micropores towards fractures and then to the producing wells. The production from the adsorbed gas has been to be found difficult to be produced compared with the free gas, as a result of different mechanisms of storage (adsorption) and the transport mechanism (surface diffusion) through shale pores system (Wua et al. 2015). Moreover, the adsorbed gas tends to behave differently in terms of density and accumulation (Ambrose, Hartman et al. 2012, Ma et al. 2016).

The prospective production from adsorbed gas is influenced by many factors such as reservoir permeability and the fracture network (Pan and Connell 2015). The initial reservoir pressure and the amount of total organic content are playing the main role in the adsorption capacities (Ansari, Merletti et al. 2019). The adsorption capacities of shales and TOC show a direct linear correlation, where the adsorbed gas typically increases with increasing TOC (Weniger, Kalkreuth et al. 2010). With increasing the thermal maturation, the adsorption capacities are found to increase as a result of generated microporosity from the organic matter 
Fig. 1 The production profile of free and adsorbed gas for Barnett shale reservoir calculated by our predictive simulation model

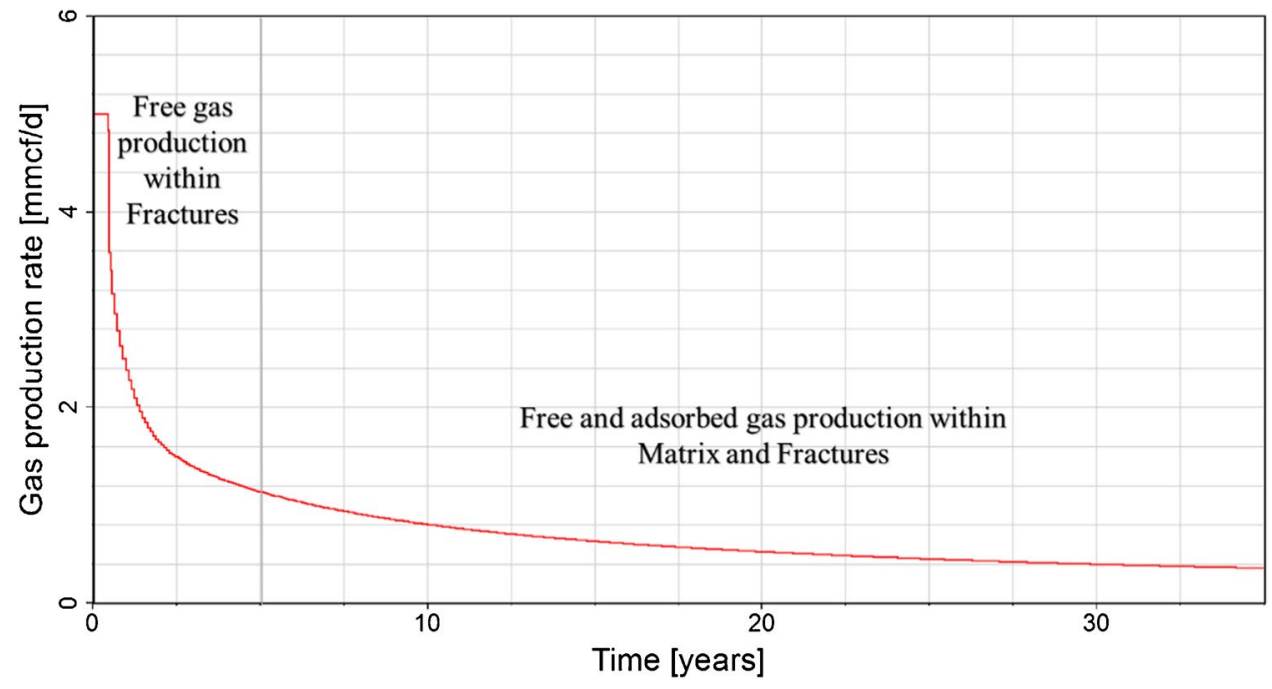

(Gasparik, Bertier et al. 2013). In addition, it has been proven that clay minerals can also adsorb gases and vapours ( $\mathrm{Lu}, \mathrm{Li}$ et al. 1995). In respect to pressure, the adsorption capacity, hence the original adsorbed gas in place, yields a general trend of increasing with pressure. Fig. 2 shows how the adsorbed $\mathrm{CH}_{4}$ typically relates in a non-linear correlation to pressure in different shales samples. However, the adsorption capacity tends to increase slowly at high pressure. This observed change in adsorption behaviour at high pressure environment could be attributed to the completion of mono-layer adsorption, which is typically followed by the equilibrium saturation (Nuttal, Eble et al. 2005).

\section{Multi-porosity and multi-permeability model}

Shale gas reservoirs have two distinct types of porosity, the fractures and matrix porosity. The matrix pores are in nanoscale and only occupied by free gas. The analysis of threedimensional high-resolution imaging has recently showed a large and interconnected pores of organic pockets within shale matrix (Kang et al. 2010). The organic pores have a much smaller length compared to the inorganic matter (typically less than $10 \mathrm{~nm}$ ) (Adesida et al. 2011a) and are more likely than matrix to be interconnected (Verba et al. 2016). The contribution of organic pores lies in the range of 34 to more than $50 \%$ to the total pore volume (Schettler and Parmely 1991, Passey, Bohacs et al. 2010, Hardy 2019). According to the complex mechanisms by which gas is trapped in shale structure, in this work, a multi-porosity and multi-permeability model became essential to simulate gas transport behaviour from sub-matrix cells to the primary matrix cells towards the natural and/or the induced fractures, and then to the wellbore.

\section{Gas adsorption isotherm}

In shale reservoirs, the original gas in place is estimated in terms of gas content for both free and adsorbed gas. The relative contribution of free vs adsorbed gas varies with the total organic content, reservoir pressure and temperature, pore size distribution, and rock texture (Bustin, Bustin et al. 2008). The free gas reserve is defined using shale porosities
Fig. 2 Methane adsorption isotherms analysis at a range of pressure values calculated for New Albany Shale and Ohio Shale (Nuttal, Eble et al. 2005)
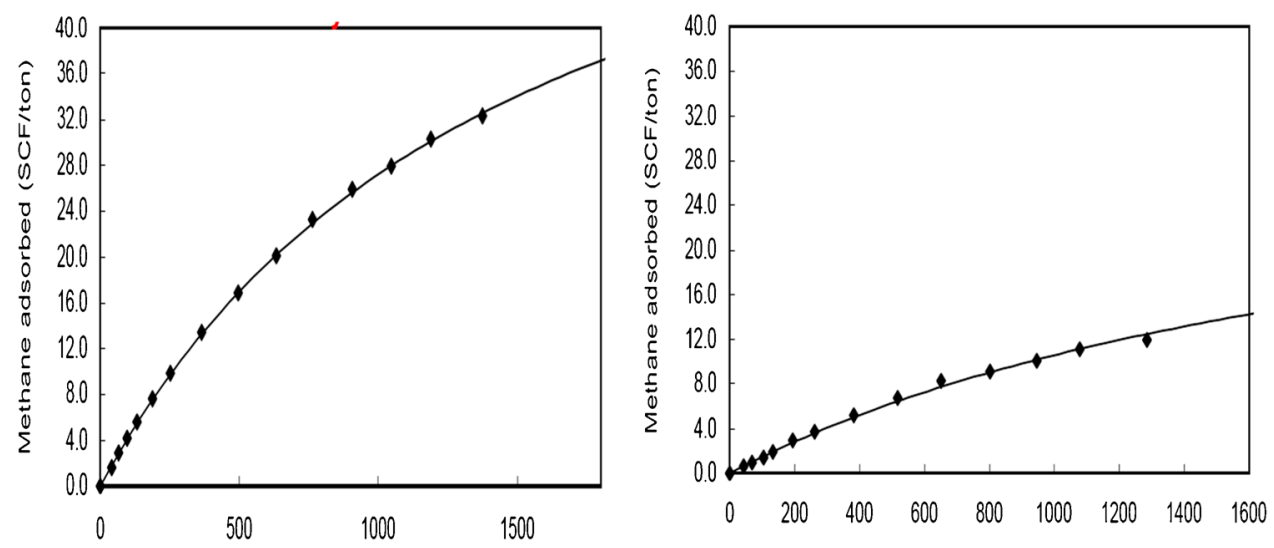
(fractures, organic, and inorganic). In this study, Langmuir isotherm (monolayer molecules of the adsorbed gas) was used to define the shale gas adsorption and desorption process. Langmuir isotherms can be expressed as shown in Eq.

(1) (Merey and Sinayuc 2016):

$V_{p}=\frac{V_{l} P}{P_{l}+P}$

where

$\mathrm{V}_{\mathrm{p}}$ is the predicted amount of adsorbed gas at gas pressure $P$,

$V_{l}$ is Langmuir's volume,

$P_{l} \quad$ is Langmuir's pressure at which $50 \%$ of gas is adsorbed.

Commonly, Langmuir isotherm is the most applied kinetic model for shale gas adsorption and desorption process (Li, Mehmani et al. 2013); it is a simple and practical model which is based upon two main assumptions. Firstly, molecules of free and adsorbed gas are in a state of dynamic equilibrium at constant temperature. Secondly, the adsorption thickness is a monolayer molecule of the adsorbed gas (Yu, Sepehrnoori et al. 2016). In contrast, Emmet and Teller (BET) isotherm is a model in which infinite number of multi-layer adsorption is taken into account (Clarkson, Bustin et al. 1997).

Whilst Langmuir isotherm has been proven in previous study to fit accurately over a range of pressure and temperature (Clarkson, Bustin et al. 1997), it may not be always valid for organic-rich shale of a large effective pore size greater than $10 \mathrm{~nm}$ (Chai, Yang et al. 2019). Therefore, in this work, it was decided not to consider the effect of multilayer adsorption. The main reason for this is that organic porosity of $2 \%$ was defined in our predictive model, which is an indication of small effective organic pore size typically $<10 \mathrm{~nm}$ (Kang et al. 2010). Consequently, multi-layer adsorption model consideration in this study will result in underestimating in free gas volume that occupies the organic pores. Moreover, in respect to surface diffusion, the upper layer may not necessarily contribute if the lower layer is not completely formed (Brunauer and Emmett 1937). Hence, the formation of multi-layers of adsorption may not play a significant role in our undertaken investigation.

\section{Gas transport mechanism}

Gas transport in shale reservoirs is a complex flow process as a result of different gas storage mechanisms and pore size distribution. Gas flow mechanism in shale reservoirs varies in organic from inorganic pores and is significantly different from that in conventional gas reservoirs (Wua, Li et al. 2015). Typically, within shale pores system, gas flow comes from the matrix region to fractures region to feed the wells (Shi et al. 2013). With regard to the channel size, Darcy's law can be used to simulate the free gas flow within the fractures network (Schepers et al. 2009a). In contrast, the capillary size is considerably much smaller in the matrix pores; therefore, the free gas transport is subjected to diffusion transport mechanism (Wasaki and Akkutlu 2015a, b). Finally, in inorganic pores, where the gas is adsorbed on the surface organic matter, desorption process governs gas transport to fractures and to inorganic matrix pores. Consequently, accurate simulation of shale gas reservoirs needs to consider the effects of different flow and storage mechanisms associated with the different pore types described above. Therefore, a combination of desorption, diffusion, and Darcy flow mechanisms were considered in our simulation study.

\section{Methodology of reservoir modelling}

\section{Model development}

The numerical reservoir simulation technique has been one of the effective tools used to analyse the realistic flow mechanism of free and desorbed shale gas. In this study, Eclipse-300 compositional reservoir simulator was used to simulate gas production for the Barnett shale reservoir. The numerical simulation model of the Barnett shale reservoir was generated using data in public domain (Table 1). The key input parameters were defined in the model within the range which consists with that presented in literature for the realistic shale. Tables 2 and 3 show the reservoir parameters and Langmuir constants of $\mathrm{CH}_{4}$ for Barnett shale gas reservoir (Frantz, Sawyer et al. 2005, Grieser et al. 2006, Gale, Reed et al. 2007, Du et al. 2009, Adesida et al. 2011a, Mengal and Wattenbarger 2011, Ambrose, Hartman et al. 2012, Shi et al. 2013, Wu and Aguilera 2013, Kim, Cho et al. 2017, Hardy 2019).

Many previous simulation studies used the traditional dual-porosity model which neglects the transient behaviour within matrix region (Schepers et al. 2009a, Eshkalak et al. 2014). To accurately simulate the storage and transient behaviour of the matrix region, multi-porosity and

Table 1 The fracture data used for the Barnett model

\begin{tabular}{lll}
\hline Parameter & Value & Unit \\
\hline Hydraulic fracture spacing & 300 & feet \\
Hydraulic fracture height & 200 & feet \\
Hydraulic fracture width & 0.15 & feet \\
Total number of fractures & 25 & \\
Fracture half length & 350 & feet \\
Number of stages & 5 & \\
\hline
\end{tabular}


Table 2 The reservoir properties of Barnett shale reservoir

\begin{tabular}{lll}
\hline Reservoir parameter & Value, reference & Unit \\
\hline Matrix porosity & $2-6$ (Frantz. 2005) & $\%$ \\
Fracture porosity & $1-6$ (Du, Zhang et al. 2009) & $\%$ \\
Organic porosity & 2 (Hardy 2019) & $\%$ \\
Matrix permeability & $0.0001-0.005$ (Grieser, Shelley et al. & $\mathrm{mD}$ \\
& 2006 ; (Wu and Aguilera 2013) & \\
Fracture permeability & 0.001 (Kim, Cho et al. 2017) & $\mathrm{mD}$ \\
Organic permeability & 0.0015 (Du et al. 2009) & $\mathrm{mD}$ \\
Adsorption capacity & $50-200$ (Du et al. 2009) & $\mathrm{sfc} / \mathrm{ton}$ \\
TOC & $4-8$ (Frantz. 2005) & $\%$ \\
Organic density & 166 (Ambrose, Hartman et al. 2012) & $\mathrm{lb} / \mathrm{ft}^{3}$ \\
Bulk density & 156 (Ambrose, Hartman et al. 2012) & $1 \mathrm{~b} / \mathrm{ft}^{3}$ \\
Pressure gradient & $0.43-0.52$ (Adesida et al. 2011a) & $\mathrm{psi} / \mathrm{ft}^{3}$ \\
Reservoir temperature & 200 (Mengal and Wattenbarger & $\mathrm{F}^{\circ}$ \\
& $2011)$ & \\
Depth & $6000-9000$ (Frantz et al. 2005) & $\mathrm{ft}$ \\
Gross thickness & $100-1000$ (Frantz et al. 2005) & $\mathrm{ft}=$ \\
Diffusion coefficients & 0.1116 (Shi et al. 2013) & $\mathrm{ft}^{2} / \mathrm{day}$ \\
\hline
\end{tabular}

Table 3 Langmuir constants of $\mathrm{CH}_{4}$ for Barnett shale gas reservoir (Frantz, Sawyer et al. 2005, Mengal and Wattenbarger 2011)

\begin{tabular}{lll}
\hline $\begin{array}{l}\text { Langmuir } \\
\text { constants of } \\
\mathrm{CH}_{4}\end{array}$ & Value & Unit \\
\hline $\mathrm{V}_{\mathrm{L}}$ & 880 & scf/ton \\
$\mathrm{P}_{\mathrm{L}}$ & 400 & psi \\
\hline
\end{tabular}

multi-permeability models were employed in our predictive model. Thus, our model can predict gas flow from submatrix cells to the primary matrix cells towards the natural and/or the induced fractures, and then to the wellbore.

Mass accumulation and flow within matrix region are dominated by the adsorption and desorption process. Therefore, an accurate capture of adsorption-desorption behaviour is of crucial importance for shale gas modelling. The instant sorption option was used in our model to offer an effective way to represent the gas volumes (free and adsorbed) simultaneously within the organic matrix pores.

In this model, a horizontal producer well and five stages of hydraulic fractures were generated in the middle of the reservoir segment intersecting. Table 1 shows the fracture parameters used for the simulation model. For more accurate gas flow simulation, a local grid refinement option was also generated around the fractures. Given that the gas is nonwetting phase in inorganic matter (Daigle et al. 2015), conceptually, two relative permeability curves were assigned in this case study for shale bulk and organic matter separately.

The shale reservoir of interest in this work is the Barnet shale reservoir, which is a fine-grained and rich-organic sediment located in the USA. Barnett shale reservoir was discovered in 1981 (Kenomore, Hassan et al. 2018). Currently, it is one of the most prolific shale gas producers in the USA. For numerical modelling, a segment of Barnett shale reservoir was simulated using 3D reservoir model with dimensions of $1,750 \times 1,100 \times 200$ feet. The multi- porosity model has a grid size of $40 \times 13$ cells in $X, Y$ directions and 7 cells in $\mathrm{Z}$ direction. The cells in $\mathrm{Z}$ direction were subdivided into $1+1+5$, representing fracture, matrix and sub-matrix cells respectively. Fig. 3 shows by a $2 \mathrm{D}$ view the matrix and fractures for Barnett shale model represented by fluid in place regions 1 and 2, respectively; the figure also illustrates the induced fracture stages and the refined grid cells.

The first stage of prediction was carried out to compare the fractions of adsorbed gas to the total gas production at various reservoir depths ranging from 3,000 to 11,000 feet at a fixed value of TOC. Afterwards, sensitivity cases were generated for every reservoir depth with varying TOC from 4 to $8 \%$ to capture the contribution of produced adsorbed gas and the corresponding effect of TOC for each case.

\section{Calibration of the shale mechanistic model}

In our simulation model, the initial conditions, adsorption capacities, the fractions of free, and adsorbed gas volumes to the total gas in place at given reservoir pressures, and the recoverable volume were adopted to match the typical data for the Barnett shale reservoir.

To calibrate the shale mechanistic model, static and dynamic simulations were conducted to match the gas content and the recovery factor of Barnett shale. The original gas in place is estimated in terms of gas content for both free and adsorbed gas. Shale porosities (fractures and inorganic) describe the free gas whereas Langmuir isotherms define the relation between the adsorption capacity and pressure at constant temperature. Overall, to estimate the total original gas in place for our predictive model, the gas content (scf/ ton) was estimated by Barnett shale reservoir data given in literature.

For model calibration and result robustness, our base simulation model was applied to couple Langmuir isotherms and volumetric calculations, estimating the gas content for free and adsorbed gas at different values of reservoir pressure. The estimation of adsorbed gas content was made by realistic Langmuir isotherms published in literature (Frantz, Sawyer et al. 2005, Mengal and Wattenbarger 2011).

In order to validate the predictive model, the simulated fractions of adsorbed and free gas volumes to the total gas in place against the fractions extracted from core data analysis were matched for the Barnett shale reservoir. This is shown in Fig. 4 (Lancaster et al. 1992).

To increase the reliability of validation, it was carried out in terms of volume fractions instead of gas, eliminating the 


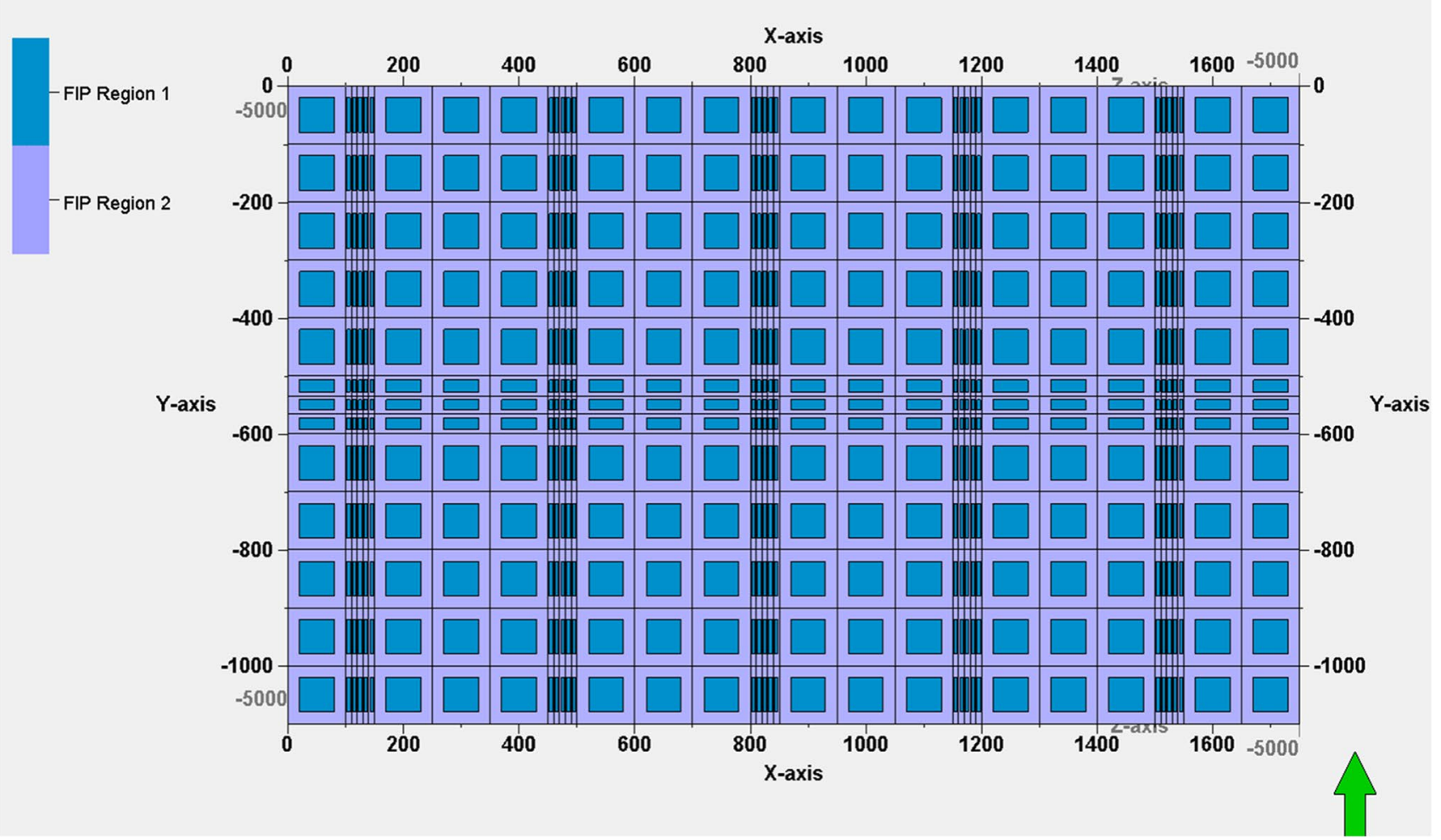

Fig. 3 2D view of the Barnett shale reservoir model

Fig. 4 Typical gas content measured by core analysis for Barnett shale reservoirs at depth of 7640 feet and $4 \%$ of TOC reproduced from (Lancaster et al. 1992)

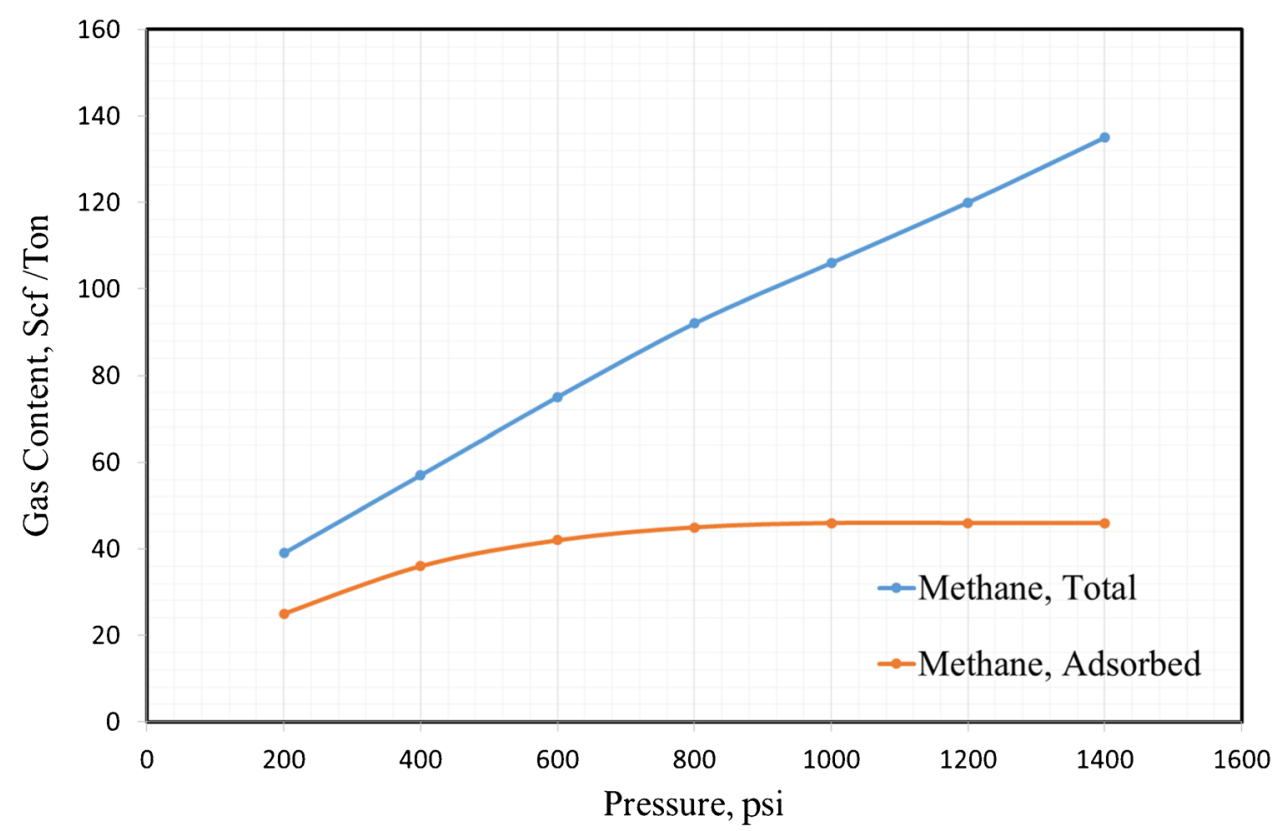

effect of crushed porosities and in the measured samples. Figure 5 displays an accepted match between the estimated fractions from the calibrated model and by core analysis.

For further validations, the estimated recoverable reserve across the typical range of pressures and TOC that resulted from the calibrated model were adopted to lie in the range of 10 to $20 \%$ as shown in Fig. 6 which typically matches the reported recovery factors of Barnett shale (Frantz, Sawyer et al. 2005). 
Fig. 5 The simulated fractions of adsorbed and free gas volumes are compared to fractions measured by core analysis for Barnett shale reservoirs at depth of 7640 feet and $4 \%$ of TOC
Fig. 6 the recovery factors estimated by our calibrated model at $8 \%$ of TOC
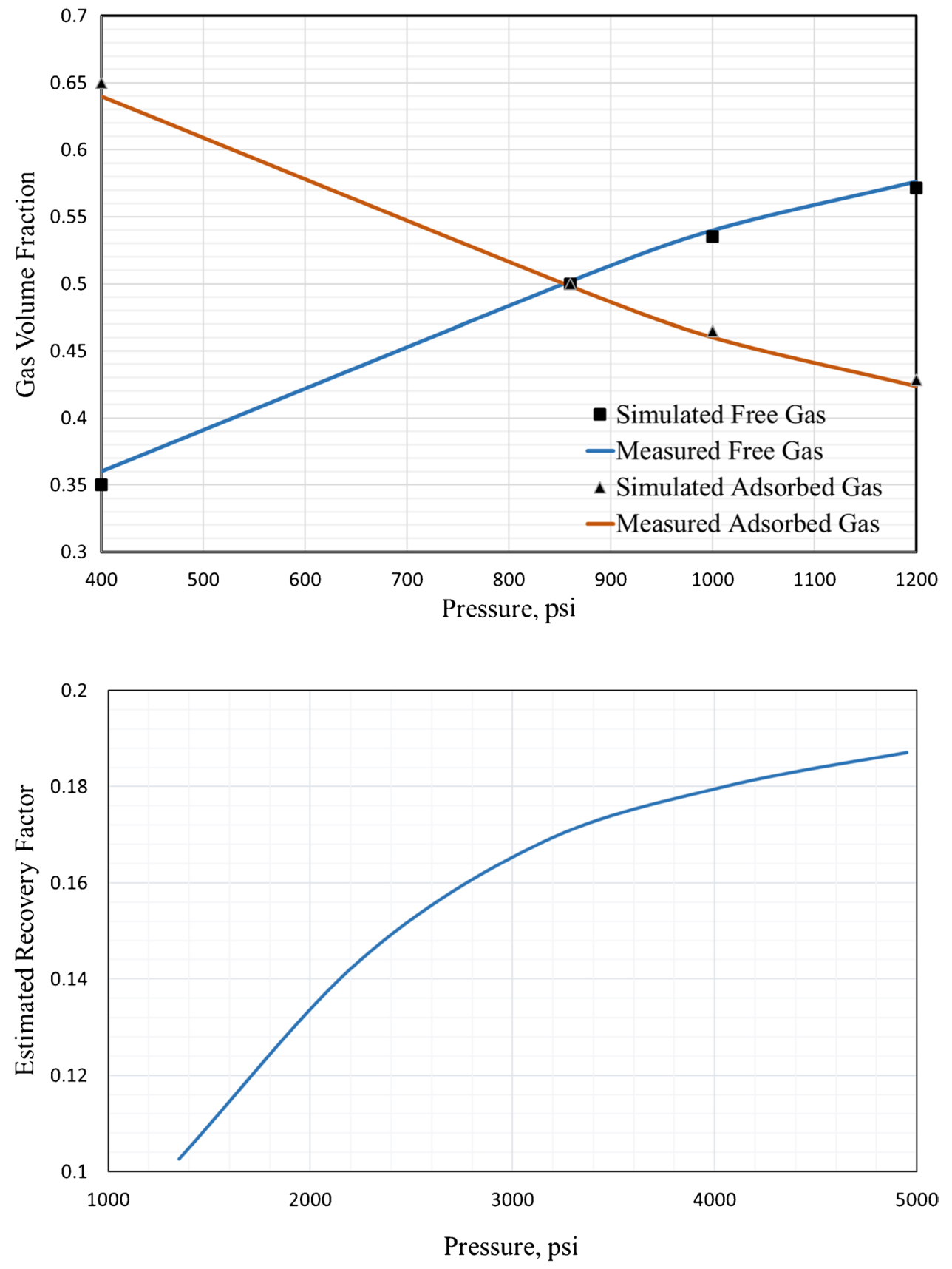

\section{Results and discussion}

\section{Effect of reservoir pressure on adsorbed gas production}

In order to investigate the impact of reservoir pressure on the adsorbed gas production, our predictive model quantified the contribution of adsorbed and free gas for 40 years in regard to increasing in reservoir depth from 3,000 to 11,000 feet (i.e. pressure) within TOC range of 4 to $8 \%$. The results obtained from the sensitivity runs show that adsorbed gas production strongly decreased with increasing reservoir depth regardless of TOC, as shown in Fig. 7. For example, at a given TOC of $4 \%$, the contribution of adsorbed gas production decreased from 18 to $1 \%$ with increasing reservoir depth from 3,000 to 11,000 feet.

Based on the simulation results, it can be concluded that desorption phenomenon becomes insignificant storage mechanism in deep shale reservoirs, particularly for low TOC shales. Our findings are also supported by the experimental results (Ansari, Merletti et al. 2019), who reported that adsorbed gas contributed by $21 \%$ of the total produced gas at 800 psi which is equivalent to 1,770 feet with Barnett 
Fig. 7 Fractions of produced adsorbed gas to the total cumulative production at different reservoir depths at a range of $4-8 \%$ of $\mathrm{TOC}$

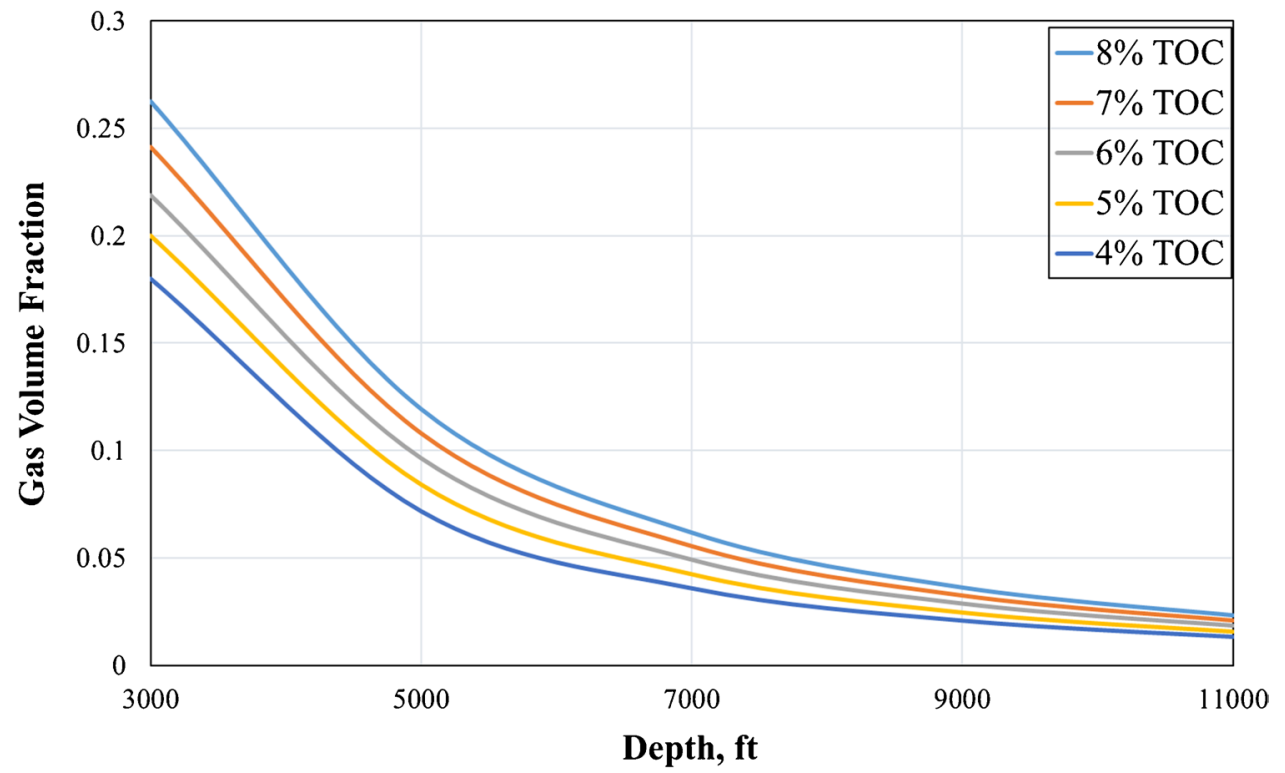

shale pressure gradient. Their observations also suggest that the adsorbed gas likely contributes to $50 \%$ of total gas production at the abandonment pressure.

It is understandable that desorption process is mainly controlled by pressure decline in matrix pores ( $\mathrm{Yu}$ and Sepehrnoori 2014); therefore, in high-pressure shales, since very low-pressure decline takes place due to ultra-low matrix permeability, the adsorbed gas is less likely to be desorbed from the organic matter surface. It can be seen from Fig. 8 that the reservoir pressure declined approximately by only $30 \%$ from the initial pressure across 40 years of continuous production. As shown in Fig. 7, for shale reservoirs deeper than 5,000 feet, the contribution of the adsorbed gas is less than $12 \%$ across 40 years of production; hence, it can be concluded that the free gas flow within matrix pores to the induced fractures is the dominant contributor of this stage of production. This explains that fracture and matrix permeabilities have been found to be the key significant parameters at early and late times of shale gas production (Dahaghi and Mohaghegh 2011, Yu and Sepehrnoori 2014, Pan and Connell 2015).

Our results imply that adsorbed gas plays a minor role in deep shale reservoirs production. Consequently, this work underscores the importance of Langmuir isothermal behaviour to manage and predict the performance of shale gas production in shallow shale plays. Moreover, the results prove that an enhancement in shale matrix permeability can lead to a higher adsorbed and free gas cumulative production since the pressure difference between the adsorbed and free gas increases.
Fig. 8 The simulated pressure decline profile for $4 \%$ TOC and 4000 psi initial pressure

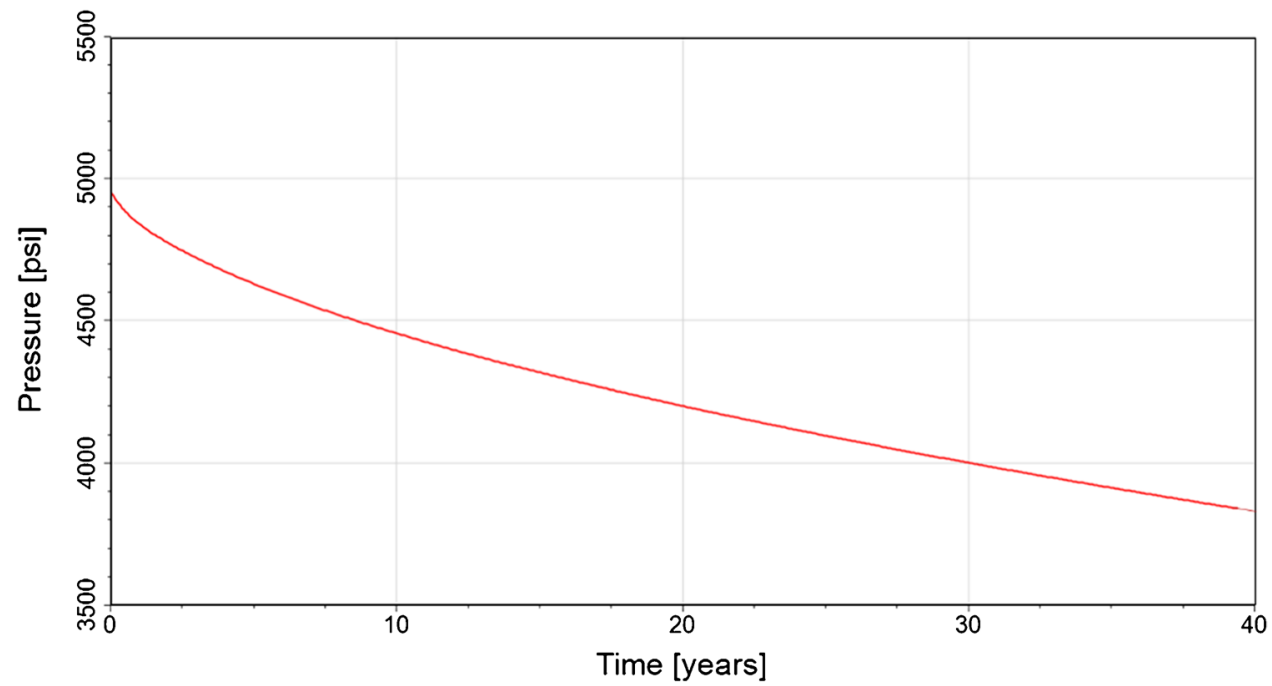




\section{Effect of TOC on adsorbed gas production}

In this study, a range of 4 to $8 \%$ of TOC was considered to analyse the effect of increasing TOC on the adsorbed gas production within a range of 3,000 to 11,000 feet of reservoir depth. As shown in Fig. 9, the predicted adsorbed gas from the simulation model shows that increasing TOC increases the contribution of adsorbed gas to the total gas production for a given reservoir depth. For example, increasing TOC from 4 to $8 \%$ results in increasing the cumulative adsorbed gas production from 195 to $335 \mathrm{MMSCF}$ at the same reservoir depth of 5,000 feet.

The observed correlation between TOC and the adsorbed gas production could be attributed to the fact that the amount of gas originally adsorbed on the surface of organic matter in rich-organic shales reservoirs is a function of the pressure and the volume of organic matter in shale matrix. However, the impact of TOC on the contribution of adsorbed gas production becomes minor with increasing reservoir depth. This observation seems to be consistent with that presented in literature, for instance, the simulation results study presented by Pan et al. (Pan and Connell 2015), which argued that the increasing of adsorbed gas (i.e. total organic content) increases the cumulative production from both free and adsorbed gas. However, our study proves that the amount of the desorbed gas has less contribution to the total production in deep shale reservoirs compared to shallow reservoirs.

This combination of findings offers several contributions to the existing knowledge by providing insight into the characterisation, development, and prediction of shale gas reservoirs with respect to pressure and TOC. Also, this work has important implications related specifically to the application of enhanced shale gas recovery by $\mathrm{CO}_{2}$ injection. Our results suggest that $\mathrm{CO}_{2}$ injection in shallow shale (rich in TOC) reservoirs would give a much better performance to unlock adsorbed gas compared to deep shales, since the desorbed gas is more likely to be desorbed and the injected stream of $\mathrm{CO}_{2}$ could be potentially sequestrated.

\section{Conclusions and implications}

This work aimed to examine the effect of the reservoir depth coupled with TOC on the adsorbed gas production. A sensitivity study was performed to examine the desorption behaviour in shale reservoirs. The results of this study show that reservoir depth has a significant effect on the contribution of adsorbed gas to shale gas production. Regardless of TOC, adsorbed gas production decreases with increasing reservoir depth. Whilst this contribution increases with increasing TOC, the impact of TOC on the contribution of adsorbed gas production becomes minor with increasing reservoir depth. These results suggest that adsorbed gas may play an important role (12-26\%) in total gas production in shallow shale plays below 4,000 feet.

This study highlights the importance of Langmuir isothermal behaviour in shallow shale plays and contributes to existing research by providing insight into characterisation, development, and prediction of shale gas reservoirs with respect to reservoir depth and TOC; it presents a significant contribution to the energy transition to net-zero target of $\mathrm{CO}_{2}$ emissions by demonstrating important insights into the application of enhanced shale gas recovery and $\mathrm{CO}_{2}$ sequestration. Based on the simulation results (shallow
Fig. 9 the cumulative production from adsorbed gas volumes with a range of $4-8 \%$ TOC

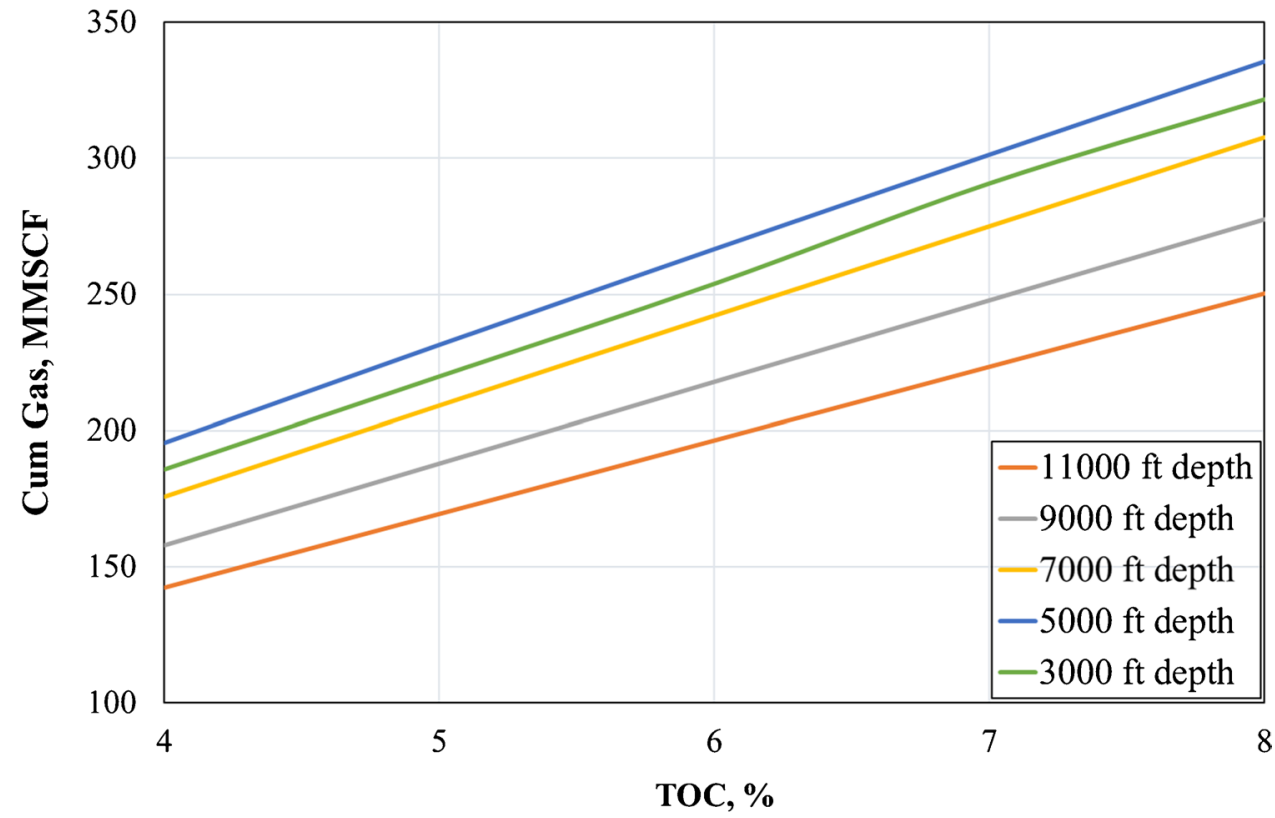


shale reservoirs have been proven in our study to produce more adsorbed gas compared to deep shales), injecting $\mathrm{CO}_{2}$ into shallow shale reservoirs (rich in TOC) would give an improved outcome to unlock the adsorbed gas and sequestrate $\mathrm{CO}_{2}$

Acknowledgements The simulation work done for this study was carried out by Eclipse reservoir compositional simulator license provided by Schlumberger.

Funding Open Access funding enabled and organized by CAUL and its Member Institutions

\section{Declarations}

Conflict of interest The authors declare no competing interests.

Open Access This article is licensed under a Creative Commons Attribution 4.0 International License, which permits use, sharing, adaptation, distribution and reproduction in any medium or format, as long as you give appropriate credit to the original author(s) and the source, provide a link to the Creative Commons licence, and indicate if changes were made. The images or other third party material in this article are included in the article's Creative Commons licence, unless indicated otherwise in a credit line to the material. If material is not included in the article's Creative Commons licence and your intended use is not permitted by statutory regulation or exceeds the permitted use, you will need to obtain permission directly from the copyright holder. To view a copy of this licence, visit http://creativecommons.org/licenses/by/4.0/.

\section{References}

Adesida AG, Akkutlu I, Resasco DE, Rai CS (2011) Characterization of Barnett shale kerogen pore size distribution using DFT analysis and grand canonical Monte Carlo simulations. SPE Annual Technical Conference and Exhibition. Denver, Colorado, USA, Society of Petroleum Engineers: 14

Adesida AG, Akkutlu IY, Resasco DE, Rai CS (2011) Kerogen pore size distribution of Barnett shale using DFT analysis and Monte Carlo simulations

Ambrose RJ, Hartman RC, Diaz-Campos M, Akkutlu IY, Sondergeld CH (2012) Shale gas-in-place calculations part I: new pore-scale considerations. SPE Journal 17(01):219-229

Ansari R, Merletti G, Gramin P, Armitage P (2019) More accurate quantification of free and adsorbed gas in shale reservoirs. Petrophysics 60(05):560-584

Brunauer S, Emmett PH (1937) The use of low temperature van der Waals adsorption isotherms in determining the surface areas of various adsorbents. Journal of the American Chemical Society 59(12):2682-2689

Bumb AC, McKee CR (1988) Gas-well testing in the presence of desorption for coalbed methane and devonian shale. SPE Formation Evaluation 3(01):179-185

Bustin AMM, Bustin RM, Cui X (2008) Importance of fabric on the production of gas shales. SPE Unconventional Reservoirs Conference. Keystone, Colorado, USA, Society of Petroleum Engineers: 29

Bybee K (2009) Proper evaluation of shale-gas reservoirs leads to more-effective hydraulic-fracture stimulation. Journal of Petroleum Technology 61(07):59-61
Chai D, Yang G, Fan Z, Li X (2019) Gas transport in shale matrix coupling multilayer adsorption and pore confinement effect. Chemical Engineering Journal 370:1534-1549

Clarkson C, Bustin R, Levy J (1997) Application of the mono/multilayer and adsorption potential theories to coal methane adsorption isotherms at elevated temperature and pressure. Carbon 35(12):1689-1705

Dahaghi AK, Mohaghegh SD (2011) Numerical simulation and multiple realizations for sensitivity study of shale gas reservoirs. SPE Production and Operations Symposium. Oklahoma City, Oklahoma, USA, Society of Petroleum Engineers: 11

Dai J, Qin S, Hu G, Ni Y, Gan L, Huang S, Hong F (2019) Major progress in the natural gas exploration and development in the past seven decades in China. Petroleum Exploration and Development 46(6):1100-1110

Daigle H, Ezidiegwu S, Turner R (2015) Determining relative permeability in shales by including the effects of pore structure on unsaturated diffusion and advection. SPE Annual Technical Conference and Exhibition. Houston, Texas, USA, Society of Petroleum Engineers: 22

Du C, Zhang X, Melton B, Fullilove D, Suliman ETB, Gowelly SI, Grant D, Calvez J (2009) A workflow for integrated Barnett shale gas reservoir modeling and simulation. Latin American and Caribbean Petroleum Engineering Conference. Cartagena de Indias, Colombia, Society of Petroleum Engineers: 12

Frantz JH, Sawyer WK, MacDonald RJ, Williamson JR, Johnston D, Waters G (2005) Evaluating Barnett shale production performance-using an integrated approach. Society of Petroleum Engineers, SPE annual technical conference and exhibition

Freeman CM, Moridis G, Ilk D, Blasingame TA (2013) A numerical study of performance for tight gas and shale gas reservoir systems. Journal of Petroleum Science and Engineering 108:22-39

Gale JF, Reed RM, Holder J (2007) Natural fractures in the Barnett Shale and their importance for hydraulic fracture treatments. AAPG bulletin 91(4):603-622

Gasparik M, Bertier P, Gensterblum Y, Ghanizadeh A, Krooss BM, Littke R (2013)

Godec M, Koperna G, Petrusak R, Oudinot A (2014) Enhanced gas recovery and $\mathrm{CO} 2$ storage in gas shales: a summary review of its status and potential. Energy Procedia 63:5849-5857

Grieser WV, Shelley RF, Johnson BJ, Fielder EO, Heinze JR, Werline JR (2006) Data analysis of Barnett shale completions. SPE Annual Technical Conference and Exhibition. San Antonio, Texas, USA, Society of Petroleum Engineers: 12

Hardy J (2019) Characterization of organic pores within high-maturation shale gas reservoirs. SPE Annual Technical Conference and Exhibition. Calgary, Alberta, Canada, Society of Petroleum Engineers: 6

IEA (2019) "World Energy Outlook 2019."

Ji L, Zhang T, Milliken KL, Qu J, Zhang X (2012) Experimental investigation of main controls to methane adsorption in clayrich rocks. Applied Geochemistry 27(12):2533-2545

Kang SM, Fathi E, Ambrose RJ, Akkutlu IY, Sigal RF (2010) CO2 storage capacity of organic-rich shales. SPE Annual Technical Conference and Exhibition. Florence, Italy, Society of Petroleum Engineers: 17

Kenomore M, Hassan M, Dhakal H, Shah A (2018) Economic appraisal of shale gas reservoirs. SPE Europec featured at 80th EAGE Conference and Exhibition. Copenhagen, Denmark, Society of Petroleum Engineers: 19

Kim TH, Cho J, Lee KS (2017) Evaluation of CO2 injection in shale gas reservoirs with multi-component transport and geomechanical effects. Applied Energy 190:1195-1206

Lancaster DE, McKetta SF, Hill RE, Guidry FK, Jochen JE (1992) Reservoir evaluation, completion techniques, and recent results from Barnett shale development in the Fort Worth Basin 
Li B, Mehmani A, Chen J, Georgi D, Jin G (2013) The condition of capillary condensation and its effects on adsorption isotherms of unconventional gas condensate reservoirs. SPE Annual Technical Conference and Exhibition

Lu X-C, Li F-C, Watson AT (1995) Adsorption studies of natural gas storage in Devonian shales. SPE Formation Evaluation 10(02):109-113

Ma Y, Li B, Mezzatesta A, Jamili A (2016) Simplified local density theory for modeling adsorbed gas and estimation of gas-inplace of unconventional gas condensate reservoirs. International Petroleum Technology Conference. Bangkok, Thailand, International Petroleum Technology Conference: 23

Mengal SA, Wattenbarger RA (2011) Accounting for adsorbed gas in shale gas reservoirs. SPE Middle East Oil and Gas Show and Conference. Manama, Bahrain, Society of Petroleum Engineers: 15

Merey S, Sinayuc C (2016) Analysis of carbon dioxide sequestration in shale gas reservoirs by using experimental adsorption data and adsorption models. Journal of Natural Gas Science and Engineering 36:1087-1105

Nuttal BC, Eble C, Bustin RM, Drahovzal JA (2005) Analysis of Devonian black shales in Kentucky for potential carbon dioxide sequestration and enhanced natural gas production. Greenhouse Gas Control Technologies 7. E. S. Rubin, D. W. Keith, C. F. Gilboy et al. Oxford, Elsevier Science Ltd: 2225-2228

Pan Z, Connell LD (2015) Reservoir simulation of free and adsorbed gas production from shale. Journal of Natural Gas Science and Engineering 22:359-370

Passey K, Bohacs QR, Esch WL, Klimentidis R, Sinha S (2010) From oil-prone source rock to gas-producing shale reservoir - geologic and petrophysical characterization of unconventional shale gas reservoirs. International Oil and Gas Conference and Exhibition in China. Beijing, China, Society of Petroleum Engineers: 29

Schepers KC, Gonzalez RJ, Koperna GJ, Oudinot AY (2009) Reservoir modeling in support of shale gas exploration. Latin American and Caribbean Petroleum Engineering Conference. Cartagena de Indias, Colombia, Society of Petroleum Engineers: 17

Schettler PD Jr, Parmely CR (1991) Contributions to total storage capacity in Devonian Shales. SPE Eastern Regional Meeting. Lexington, Kentucky, Society of Petroleum Engineers: 12

Shi J, Zhang L, Li Y, Yu W, He X, Liu N, Li X, Wang T (2013) Diffusion and flow mechanisms of shale gas through matrix pores and gas production forecasting. SPE Unconventional Resources Conference Canada. Calgary, Alberta, Canada, Society of Petroleum Engineers: 19

Verba C, Crandall D, Moore J (2016) Multiscale shale pore characterization. SPE/AAPG/SEG Unconventional Resources Technology Conference. San Antonio, Texas, USA, Unconventional Resources Technology Conference: 11

Wasaki A, Akkutlu IY (2015) Dynamics of fracture-matrix coupling during shale gas production: pore compressibility and molecular transport effects. SPE Annual Technical Conference and Exhibition. Houston, Texas, USA, Society of Petroleum Engineers: 24

Wasaki A, Akkutlu IY (2015) Permeability of organic-rich shale. SPE Journal 20(06):1384-1396

Wu K, Li X, Wang C, Yu W, Guo C, Ji D, Ren G, Chen Z (2014) Apparent permeability for gas flow in shale reservoirs coupling effects of gas diffusion and desorption[SPE/AAPG/SEG Unconventional Resources Technology Conference. Denver, Colorado, USA, Unconventional Resources Technology Conference: 18

Wu P, Aguilera R (2013) Uncertainty analysis of shale gas simulation: consideration of basic petrophysical properties. SPE Unconventional Resources Conference Canada. Calgary, Alberta, Canada, Society of Petroleum Engineers: 19

Wua K, Li X, Guo C, Chen Z (2015) Adsorbed gas surface diffusion and bulk gas transport in nanopores of shale reservoirs with real gas effect-adsorption-mechanical coupling. SPE Reservoir Simulation Symposium. Houston, Texas, USA, Society of Petroleum Engineers: 31

Yu W, Sepehrnoori K (2014) Sensitivity study and history matching and economic optimization for Marcellus shale. SPE/AAPG/SEG Unconventional Resources Technology Conference. Denver, Colorado, USA, Unconventional Resources Technology Conference: 15

Yu W, Sepehrnoori K, Patzek TW (2016) Modeling gas adsorption in Marcellus shale with Langmuir and BET isotherms. SPE Journal 21(02):589-600

Zhang X, Du C, Deimbacher F, Crick M, Harikesavanallur A (2009) Sensitivity studies of horizontal wells with hydraulic fractures in shale gas reservoirs. International Petroleum Technology Conference. Doha, Qatar, International Petroleum Technology Conference: 9

Eshkalak MO, Al-shalabi EW, Sanaei A, Aybar U, Sepehrnoori K (2014) Enhanced gas recovery by $\mathrm{CO} 2$ sequestration versus refracturing treatment in unconventional shale gas reservoirs. Abu Dhabi International Petroleum Exhibition and Conference. Abu Dhabi, UAE, Society of Petroleum Engineers: 18

Schepers KC, Nuttall BC, Oudinot AY, Gonzalez RJ (2009).Reservoir modeling and simulation of the Devonian gas shale of Eastern Kentucky for enhanced gas recovery and CO2 storage. SPE International Conference on CO2 Capture, Storage, and Utilization. San Diego, California, USA, Society of Petroleum Engineers: 20

Weniger P, Kalkreuth W, Busch A, Krooss BM (2010) High-pressure methane and carbon dioxide sorption on coal and shale samples from the Paraná Basin, Brazil. International Journal of Coal Geology 84(3):190-205

Yu W, Al-Shalabi EW, Sepehrnoori K (2014) A sensitivity study of potential $\mathrm{CO} 2$ injection for enhanced gas recovery in Barnett shale reservoirs. SPE Unconventional Resources Conference. The Woodlands, Texas, USA, Society of Petroleum Engineers: 16 